\title{
0 ENSINO DE CIÊNCIAS NA FORMAÇÃO CONTINUADA DE PROFESSORES DOS ANOS INICIAIS: TENDÊNCIAS E MODELOS
}

\author{
SCIENCE EDUCATION IN THE CONTINUING EDUCATION OF \\ TEACHERS OF THE EARLY YEARS: TRENDS AND MODELS
}

\author{
EDUCACIÓN CIENTÍFICA EN LA EDUCACIÓN CONTINUA DE LOS \\ PROFESORES DE LOS PRIMEROS AÑOS: TENDENCIAS Y MODELOS
}

\author{
LAUREN LINK NILSON ${ }^{1}$ \\ NOEMI BOER ${ }^{2}$ \\ CLECI T. WERNER DA ROSA ${ }^{3}$
}

\begin{abstract}
RESUMO
Neste estudo, o ensino de Ciências, nos anos iniciais do Ensino Fundamental, é abordado na perspectiva da formação continuada de professores. Busca-se também examinar as tendências do ensino de Ciências para esta etapa da Educação Básica, presentes em teses defendidas no período 2013-2019; identificar os instrumentos de pesquisa utilizados pelos autores das teses selecionadas e analisar o modelo de formação continuada de professores. Para alcançar os objetivos propostos, foi realizada uma pesquisa exploratória a partir do Catálogo de dissertações e teses da Coordenação de Aperfeiçoamento de Pessoal de Nível Superior (CAPES) cujo critério pré-estabelecido foi o ensino de Ciências na formação continuada de professores dos anos iniciais. Constatou-se que os autores utilizaram o modelo de formação continuada crítico-reflexivo, com base em cinco tendências para o ensino de Ciências: alfabetização científica, meio ambiente, evoluções científicas e tecnológicas, corpo humano e saúde e experimentação.
\end{abstract}

Palavras-chave: Alfabetização Científica. Meio ambiente. Ciências.

\section{ABSTRACT}

In this study, the teaching of Sciences, in the initial years of elementary school, is approached from the perspective of continuing teacher education. It also seeks to examine the trends of science teaching for this stage of Basic Education, present in theses defended in the period 2013-2019; to identify the research instruments used by the authors of the selected theses and to analyze the model of continuing teacher education. To achieve the proposed objectives, an exploratory research was carried out from the Catalogue of dissertations and theses of the Coordination for the Improvement of Higher Education Personnel (CAPES) whose pre-established criterion was the teaching of Sciences in the continuing education of teachers in the initial years. It was found that the authors used the critical-reflexive continuing education model, based on five trends for science teaching: scientific literacy, environment, scientific and technological evolutions, human body and health and experimentation.

\section{Keywords: Scientific Literacy. Environment. Science.}

\footnotetext{
1 Doutorando em Educação na Universidade de Passo Fundo (UPF). Mestre em Ensino Científico e Tecnológico pela Universidade Regional Integrada do Alto Uruguai e das Missões (URI). E-mail: laurenlinknilson@gmail.com. ORCID: http://orcid.org/0000-0001-5927-5269

2 Doutora em Educação Científica e Tecnológica pela Universidade Federal de Santa Catarina (UFSC). Docente do Programa do Programa de Pós-Graduação em Ensino de Humanidades e Linguagens na Universidade Franciscana (UFN). E-mail: noemiboer@gmail.com. ORCID: http://orcid.org/0000-0002-3745-2196

3 Doutora em Educação Científica e Tecnológica pela Universidade Federal de Santa Catarina (UFSC). Docente do Programa de Pós-Graduação em Educação e do Programa de Pós-Graduação em Ensino de Ciências e Matemática na Universidade de Passo Fundo (UPF). E-mail: cwerner@upf.br. ORCID: http://orcid.org/0000-0001-9933-8834
} 


\section{RESUMEN}

En este estudio, la enseñanza de las Ciencias, en los primeros años de la escuela primaria, se aborda desde la perspectiva de la educación continua del maestro. También busca examinar las tendencias de la enseñanza de la ciencia para esta etapa de la Educación Básica, presente en las tesis defendidas en el período 2013-2019; identificar los instrumentos de investigación utilizados por los autores de las tesis seleccionadas y analizar el modelo de educación continua del profesorado. Para alcanzar los objetivos propuestos, se llevó a cabo una investigación exploratoria a partir del Catálogo de Tesis y tesis de la Coordinación para la Mejora del Personal de Educación Superior (CAPES) cuyo criterio preestableccional fue la enseñanza de las Ciencias en la educación continua del profesorado en los primeros años. Se encontró que los autores utilizaron el modelo de educación continua crítico-reflexivo, basado en cinco tendencias para la enseñanza de la ciencia: alfabetización científica, medio ambiente, evoluciones científicas y tecnológicas, cuerpo humano y salud y experimentación.

Palabras clave: Alfabetización científica. Medio ambiente. Ciencias.

\section{INTRODUÇÃO}

A formação continuada de professores dos anos iniciais do Ensino Fundamental, direcionada ao ensino de Ciências, é tema de discussão por conta da formação ampla e generalista dos docentes dessa etapa educacional. Autores, como Lima e Nardi (2020), fazem referência à insegurança docente diante das especificidades do conhecimento das diferentes áreas. Em concordância a isso, Gabini e Diniz (2012, p. 346) fazem menção ao fato, afirmando que os professores dos anos iniciais da Educação Básica "não são especialistas em cada disciplina em que lecionam, os professores sentem-se inseguros e despreparados para abordar determinados conteúdos, dada a inevitável situação de ter que fazer esclarecimentos", sendo, por vezes, alvo de perguntas inesperadas. 0 desdobramento da constatação, apontada por esses autores, requer a adoção de um modelo crítico-reflexivo pelo professor.

Nesse sentido, Gabini e Diniz (2012), com base nessa evidência, abordam esse posicionamento, exemplificando-0 com trabalhos feitos em grupo a partir de investigação e reflexão. Lima e Nardi (2020) ressaltam a importância de testar os aprendizados em sala de aula e refletir coletivamente sobre os resultados obtidos, compartilhando os problemas e/ou êxitos. Por fim, Pereira et al. (2017) mencionam o professor transformador cuja orientação envolve troca de experiências e vivências pedagógicas.

0 desenvolvimento de características crítico-reflexivas favorece o ensino de Ciências nos anos iniciais e deve ser visto como um período de inserção inicial das crianças nessa área, por isso precisa ser estimulante e prazeroso, além de adequado às suas capacidades, necessidades e interesses (LIMA; CARVALHO, 2002). Sasseron (2008, p. 6) compartilha desse mesmo entendimento e ressalta que a ideia é "de um ensino que não tenha preocupações somente com a compreensão pelos alunos de conceitos, noções, termos e ideias de ciências". Nessa perspectiva, o ensino de Ciências deve ultrapassar a simples transmissão de conhecimentos e/ou a observação de experimentos, possibilitando que o aluno faça uso de conhecimentos sobre ciências, como expressa a pesquisadora (1997).

Para tanto, é preciso ser capaz de levar para a sala de aula discussões que prestigiem o fazer científico e a relação dos saberes construídos pelos cientistas com a vida da sociedade (SASSERON, 2008). Essa necessidade também é defendida por Rosa, Perez e Drum (2007) e Bizzo (2009), quando mencionam a importância de incorporar à prática pedagógica do ensino de Ciências atividades que permitam explorar conhecimentos, com base nas situações cotidianas dos estudantes e que os estimulem a buscar e discutir conhecimentos científicos do mundo, vividos em seu dia a dia. 
Sasseron (2008) defende um ensino de Ciências por meio de propostas nas quais os alunos precisem investigar problemas e fenômenos que tenham vínculos com seu cotidiano. Em concordância, Bizzo (2009) reforça a importância de se observar em que etapa escolar o estudante se insere, adequando 0 ensino de Ciências a cada fase, para que os estudantes possam compreender a afirmação e relacioná-la a alguma situação do seu dia a dia.

0 ensino de Ciências apresenta dificuldades e desafios tanto para o professor como para 0 aluno, porém é de consenso que o docente pode contribuir efetivamente para a ampliação da capacidade de compreensão e atuação no mundo em que cada estudante se insere (BIZZO, 2009). Com base nessa contribuição, percebe-se que "apresentar as ciências como uma construção humana em que debates e controvérsias são condições para o estabelecimento de um novo conhecimento" (SASSERON, 2008, p. 6) tem se mostrado elemento motivacional positivo durante as aulas de Ciências.

Nesse sentido, quando a criança percebe que a ciência não é um conhecimento pronto, finalizado, mas sim produto de uma série de discussões e construções ao longo dos anos, ela desenvolve capacidade de questionar e buscar novas informações. De acordo com Bizzo (2009), a perspectiva ideológica da ação docente não pode se dissociar da expectativa social que recai sobre a escola, reforçando o princípio de que ensinar Ciências deve se constituir como prioridade para todas as escolas.

A pesquisa desenvolvida por Persicheto (2016) se refere ao professor dos anos iniciais da Educação Básica como um docente multidisciplinar, responsável pelo ensino de diversas disciplinas de forma simultânea. Pereira (2014), Martins (2016), Maurente (2015), Venturieri (2019) e Persicheto (2016) abordam, em suas teses, um posicionamento crítico-reflexivo frente às construções ou inovações tecnológicas e científicas, mas o ensino de Ciências não deve se limitar à transmissão de notícias sobre os produtos da ciência, deve, sim, oportunizar uma forma de planejar e coordenar pensamento e ação frente ao desconhecido. Esse ensino deve, ainda, proporcionar a todos os estudantes a oportunidade de desenvolver capacidades que neles despertem o interesse diante do desconhecido, buscando explicações lógicas e razoáveis, amparadas em elementos explorados em sala de aula (BIZZO, 2009). Nesse sentido, Sasseron (2008) reforça que as relações entre Ciência, Tecnologia e Sociedade (CTS) fazem parte, mais ou menos intensamente, do cotidiano de todas as pessoas do mundo.

Com base nessas colocações iniciais a respeito do ensino de Ciências, na presente pesquisa, busca-se responder ao seguinte questionamento: a partir de pesquisas realizadas para a elaboração de teses, no período 2013-2019, de que maneira a formação continuada de professores pode auxiliar no ensino de Ciências dos anos iniciais do Ensino Fundamental? Ainda, como objetivo geral de pesquisa, tem-se a intenção de compreender como o ensino de Ciências é abordado na formação continuada de professores nos anos iniciais do Ensino Fundamental. Especificamente, buscou-se (i) examinar as tendências do ensino de Ciências para os anos iniciais em teses defendidas no período 2013-2019; (ii) identificar os instrumentos de pesquisa utilizados pelos autores das teses selecionadas; e (iii) analisar o modelo da formação continuada de professores, utilizado pelas autoras das teses.

\section{METODOLOGIA}

A organização metodológica da presente pesquisa baseia-se na proposta de organização da análise de Bardin (2011), que propõe uma pré-análise, a exploração do material e o tratamento dos resultados, a inferência e a interpretação. 0 corpus é constituído por quatro (4) teses publicadas entre os anos de 2013-2019, no Catálogo de teses e dissertação da Coordenação de Aperfeiçoamento 
de Pessoal de Nível Superior - CAPES ${ }^{4}$. A busca foi realizada com os seguintes descritores: "formação continuada de professores" (AND) "Ciências" (AND) "ensino fundamental anos iniciais". 0 uso do operador booleano AND permite que sejam localizados os estudos que reúnem as três temáticas, podendo, a partir de sua localização, refiná-los.

Durante 0 levantamento das teses publicadas, no período estipulado, realizou-se também a pré-análise em que foram lidos os resumos e as palavras-chave. Com os descritores mencionados, foram encontradas 25 teses que abordam a formação continuada de professores dos anos iniciais, conforme Quadro 01. As teses são identificadas por T1, T2, T3 e, assim, sucessivamente.

Quadro 01 - Demonstrativo de teses relativas à formação continuada de professores dos anos iniciais do EF, período 2013-2019.

\begin{tabular}{|c|c|c|c|}
\hline TESE & ANO & NÍVEL DE ENSINO ABORDADO & CONTEÚDO ABORDADO \\
\hline T01 & 2013 & Anos iniciais do Ensino Fundamental & Matemática \\
\hline T02 & 2013 & Anos iniciais do Ensino Fundamental $\left(1^{0}, 2^{\circ}\right.$ e $3^{\circ}$ ano $)$ & Desenvolvimento profissional \\
\hline T03 & 2013 & Anos Finais do Ensino Fundamental & Educação Matemática Crítica \\
\hline T04 & 2013 & Educação Infantil - Anos Iniciais do Ensino Fundamental & Formação necessária na escola \\
\hline T05 & 2014 & $3^{0}$ ano do Ensino Fundamental & Matemática \\
\hline T06 & 2014 & Anos iniciais do Ensino Fundamental & Ciências \\
\hline T07 & 2014 & Anos iniciais do Ensino Fundamental $\left(1^{\circ}, 2^{\circ}\right.$ e $3^{\circ}$ ano $)$ & Ações de ensino e aprendizagem \\
\hline T08 & 2014 & $6^{\circ}$ ano do Ensino Fundamental & Matemática \\
\hline T09 & 2014 & Anos iniciais do Ensino Fundamental & Prática pedagógica \\
\hline T10 & 2015 & Educação Infantil Anos Iniciais do Ensino Fundamental & Ciências \\
\hline $\mathrm{T} 11$ & 2015 & Anos Iniciais do Ensino Fundamental & Matemática \\
\hline T12 & 2016 & Anos Iniciais do Ensino Fundamental & Ciências \\
\hline $\mathrm{T} 13$ & 2016 & Anos Finais do Ensino Fundamental & Matemática \\
\hline T14 & 2016 & Ensino Fundamental & Ciências/Matemática \\
\hline T15 & 2016 & Ensino Fundamental & Matemática \\
\hline T16 & 2016 & Anos iniciais do Ensino Fundamental & Experiência de formação \\
\hline T17 & 2016 & Anos Iniciais do Ensino Fundamental & Conteúdos curriculares \\
\hline T18 & 2016 & Ensino Fundamental & Educação Ambiental \\
\hline T19 & 2017 & Anos Iniciais do Ensino Fundamental & Necessidades formativas dos professores \\
\hline T20 & 2017 & Anos Iniciais do Ensino Fundamental Ensino Médio & Matemática \\
\hline $\mathrm{T} 21$ & 2017 & Anos Iniciais do Ensino Fundamental & Leitura \\
\hline T22 & 2017 & Anos Iniciais do Ensino Fundamental & Atuação de formadores de professores \\
\hline T23 & 2017 & Anos Finais do Ensino Fundamental & Matemática/Educação Ambiental \\
\hline T24 & 2018 & Ensino Fundamental & Ciências \\
\hline T25 & 2019 & Anos Iniciais do Ensino Fundamental & Ciências \\
\hline
\end{tabular}

Fonte: Plataforma CAPES

Das 25 teses localizadas, foram desconsideradas 21 que, apesar de estarem voltadas à formação continuada de professores dos anos iniciais, não se enquadravam nos objetivos da presente pesquisa. Desse modo, o corpus de análise ficou constituído por quatro (4) teses, descritas no Quadro 02.

4 A Biblioteca Eletrônica e o Catálogo são plataformas de livre acesso. 
Quadro 02 - Caracterização das teses que compõem o corpus da pesquisa.

\begin{tabular}{|c|c|c|c|c|c|}
\hline TESES & ANO & TÍTULO & AUTOR & $\begin{array}{l}\text { PROGRAMA DE } \\
\text { PÓS-GRADUAÇÃO }\end{array}$ & ESTADO \\
\hline $\mathrm{T} 1$ & 2014 & $\begin{array}{l}\text { O ensino de ciências nos anos iniciais do ensino fundamental } \\
\text { e a formação continuada de professores: implantação e } \\
\text { avaliação do programa formativo de um Centro de Ciência }\end{array}$ & $\begin{array}{l}\text { Grazielle } \\
\text { Rodrigues } \\
\text { Pereira }\end{array}$ & $\begin{array}{l}\text { UFRJ: Programa de } \\
\text { Pós-graduação em Ciências } \\
\text { Biológicas - Biofísica }\end{array}$ & RJ \\
\hline T2 & 2015 & $\begin{array}{l}\text { As contribuições de um curso de formação continuada de } \\
\text { professores que atuam nos anos iniciais acerca das concep- } \\
\text { ções epistemológicas e na relação com a prática pedagógica }\end{array}$ & $\begin{array}{l}\text { Viviane Maciel } \\
\text { Machado } \\
\text { Maurente }\end{array}$ & $\begin{array}{l}\text { UFRGS - Programa de } \\
\text { Pós-graduação Educação em } \\
\text { Ciências: Química da Vida e Saúde }\end{array}$ & $\mathrm{RS}$ \\
\hline T3 & 2016 & $\begin{array}{l}\text { A construção coletiva de aulas para o ensino de ciências: } \\
\text { uma proposta de formação continuada com professoras } \\
\text { dos anos iniciais do ensino fundamental }\end{array}$ & $\begin{array}{l}\text { Aline Juliana } \\
\text { Oja Persicheto }\end{array}$ & $\begin{array}{l}\text { UNESP: Programa de } \\
\text { Pós-graduação em } \\
\text { Educação para a Ciência }\end{array}$ & SP \\
\hline T4 & 2019 & $\begin{array}{l}\text { A formação de professores dos anos iniciais do ensino funda- } \\
\text { mental em espaços não formais na Amazônia: investigando } \\
\text { uma iniciativa no Centro de Ciência e Planetário do Pará }\end{array}$ & $\begin{array}{l}\text { Bianca } \\
\text { Venturieri }\end{array}$ & $\begin{array}{l}\text { UNESP: Programa de } \\
\text { Pós-graduação em } \\
\text { Educação para a Ciência }\end{array}$ & $\mathrm{SP}$ \\
\hline
\end{tabular}

Fonte: Plataforma CAPES

Na fase de exploração do material, para a categorização das quatro teses selecionadas, além da leitura do resumo e das palavras-chave, para identificação dos objetivos, do problema de pesquisa, do público envolvido e da metodologia utilizada, foram verificadas a introdução e o capítulo da metodologia de cada tese.

A análise, de natureza qualitativa, envolve a interpretação e extração de significado dos dados obtidos na pesquisa (HERNÁDEZ SAMPIERE; FERNANDEZ COLLAD0; BAPTISTA LUCI0, 2013). Dessa forma, mesmo após a revisão inicial da literatura, foi possível complementá-la em qualquer etapa do estudo, o que favoreceu a retomada de informações e a construção de resultados. Na terceira fase da aplicação da técnica de Bardin (2011), procedeu-se à análise propriamente dita do corpus e a interpretação dos dados encontrados.

\section{RESULTADOS E DISCUSSÕES}

Organizada em dois tópicos, esta seção compreende a descrição geral das teses, considerando-se as intervenções pedagógicas realizadas pelos pesquisadores, no formato curso de formação continuada, e a pesquisa propriamente dita, com destaque aos objetivos, problema de pesquisa, público envolvido e metodologia utilizada. Nesta seção, aponta-se também as principais tendências para 0 ensino de Ciências nos anos iniciais, identificadas nas teses analisadas. No segundo tópico, é analisada a formação continuada a partir dos modelos clássico, prático-reflexivo e emancipatório.

\section{DESCRIÇÃO GERAL DAS TESES SELECIONADAS}

Os principais dados relativos às intervenções pedagógicas com professores dos anos iniciais do Ensino Fundamental encontram-se sumarizados no Quadro 03, a seguir. 
Quadro 03 - Curso oferecido, modalidades de intervenção, carga horária e número de participantes.

\begin{tabular}{|c|c|c|c|c|c|}
\hline TESES & CURSO & MODALIDADE & $\begin{array}{l}\text { INSTRUMENTO } \\
\text { DE PESQUISA }\end{array}$ & $\begin{array}{c}\text { CARGA } \\
\text { HORÁRIA }\end{array}$ & $\begin{array}{l}\text { No PARTI- } \\
\text { CIPANTES }\end{array}$ \\
\hline $\mathrm{T} 1$ & $\begin{array}{l}\text { Curso de Formação Continuada de } \\
\text { Professores em Ciências Naturais }\end{array}$ & Presencial & $\begin{array}{l}\text { Entrevistas semiestruturadas } \\
\text { Observação participativa } \\
\text { Questionários } \\
\text { Análise documental } \\
\text { Análise de fotografias } \\
\text { Relatos verbais }\end{array}$ & $100 \mathrm{~h}$ & 90 \\
\hline T2 & Curso de extensão & Presencial & $\begin{array}{l}\text { Questionários } \\
\text { Momentos de escuta } \\
\text { Roda de diálogos } \\
\text { Elaboração de desenhos }\end{array}$ & $n / c$ & 16 \\
\hline T3 & $\begin{array}{l}\text { Formação continuada para os pro- } \\
\text { fessores dos anos iniciais do Ensino } \\
\text { Fundamental no Centro de Ciências e } \\
\text { Planetário do Pará }\end{array}$ & Semipresencial & $\begin{array}{l}\text { Encontros presenciais } \\
\text { Observação participante } \\
\text { Questionários } \\
\text { Entrevista } \\
\text { Orientação a distância } \\
\text { Ficha-síntese de observação dos professores }\end{array}$ & $40 \mathrm{~h}$ & 21 \\
\hline $\mathrm{T} 4$ & $\begin{array}{l}\text { Elaboração compartilhada de um } \\
\text { Acervo Didático com aulas de Ciências }\end{array}$ & Presencial & $\begin{array}{l}\text { Diário de campo } \\
\text { Investigação e análise de recursos didáticos }\end{array}$ & $n / c$ & 04 \\
\hline
\end{tabular}

Fonte: Elaborado pelas autoras

Nas teses selecionadas como corpus do presente estudo, há diversidade no quesito cursos, conforme se constata nas pesquisas de Persicheto (2016), Venturieri (2019), Maurente (2015) e Pereira (2014). Em três pesquisas (03), constam cursos na modalidade presencial e, em uma (01), curso na modalidade semipresencial, conforme demonstra o Quadro 3. Quanto à carga horária, nas teses T2 e T4, não consta (n/c) essa informação. Os cursos de formação continuada foram oferecidos aos professores como fator motivacional, fornecendo ao grupo um certificado de participação, do qual cada docente pôde fazer uso na sua carreira ou como comprovação de participação na atividade. Os cursos também foram um meio para a coleta de dados da pesquisa. Para complementar as informações a respeito do estudo realizado, procede-se à descrição de cada uma das teses selecionadas (T1, T2, T3 e T4).

Na tese $T 1$, intitulada 0 ensino de ciências nos anos iniciais do ensino fundamental e a formação continuada de professores: implantação e avaliação do programa formativo de um Centro de Ciência (PEREIRA, 2014), a pesquisadora teve como objetivo contribuir com a melhora da qualidade do ensino de Ciências nos anos iniciais do Ensino Fundamental, a partir da interface Museu-Universidade-Escola. Inicialmente, a autora avaliou os programas formativos para professores dos museus de ciência do Rio de Janeiro, assim como levantou o grau de inserção desses espaços junto aos docentes da região da Baixada Fluminense (RJ). Na metodologia, de cunho quali-quantitativo, a autora utilizou entrevistas semiestruturadas, observação participativa, questionários e análise documental. Com base nesse método, a autora respondeu ao seguinte questionamento: quais ações de formação continuada, desenvolvidos por Museus ou Centros de Ciência, podem proporcionar ambiente fértil ao professor para atuar como agente ativo no contexto escolar, visando a transformá-lo?

Dessa forma, Pereira (2014), por meio da pesquisa realizada em museus de Ciência, constatou a carência de programas formativos aos docentes dos anos iniciais. Observou-se, em sua tese, a 
crítica quanto ao predomínio de atividades de curta duração, sem espaço para debates e reflexões acerca do ensino de Ciências. Esse levantamento de dados da pesquisadora serviu como base para 0 desenvolvimento e avaliação do programa de formação continuada de professores do Espaço Ciência InterAtiva (ECI), a partir do curso de formação continuada. No processo de avaliação do curso de formação continuada, durante a coleta de dados, foram aplicados questionários pela pesquisadora, análise de fotografias, relatos verbais dos sujeitos da pesquisa e entrevistas semiestruturadas, em que a interpretação dos dados foi norteada pela técnica da análise de conteúdo.

No estudo realizado por Pereira (2014), os resultados demonstraram que a Baixada Fluminense precisa de programas formativos em Ciências Naturais, uma vez que os docentes entrevistados não reconheciam a relevância da disciplina de Ciências para seus alunos, bem como desconheciam 0 potencial pedagógico dos museus. Com o final do curso, a maior parte dos professores apresentou mudanças significativas no ensino da disciplina, sobretudo, mediante a articulação entre as diferentes disciplinas do currículo escolar. As atividades práticas trabalhadas ao longo do curso motivaram intrinsecamente os professores, a partir da introdução de novas metodologias em sala de aula, além do fomento a mudanças no contexto escolar. Entende-se, portanto, que a pesquisa realizada por Pereira evidenciou a necessidade de ampliação de ações formativas aos professores dos anos iniciais da educação básica, a fim de promoverem a formação de docentes crítico-reflexivos e demoverem práticas pedagógicas que inibem o interesse da criança pelas Ciências. Dessa forma, com base na pesquisa de Pereira, a parceria museu, escola e universidade tende a fornecer resultados significativos no processo de mudança na educação, possibilitando, inclusive, a formação de futuros cientistas.

Na tese T2, intitulada As contribuições de um curso de formação continuada de professores que atuam nos anos iniciais acerca das concepções epistemológicas e sua relação com a prática pedagógica (MAURENTE, 2015), organizada em três artigos e quatro objetivos, o interesse da autora foi: (i) investigar como a epistemologia, como saber social e pessoal na Educação Infantil e nos Anos Iniciais do Ensino Fundamental, tem sido discutida nas produções acadêmico-científicas do Encontro Nacional de Pesquisa em Ensino de Ciências (ENPEC); (ii) identificar as concepções epistemológicas dos professores que atuam nos Anos Iniciais e como essa concepção se apresenta em suas práticas educativas; (iii) dialogar e refletir, em decorrência de um curso de formação continuada sobre a concepção epistemológica de ontem, de hoje e do amanhã, como essas concepções influenciaram, influenciam e poderão influenciar a prática educativa na escola; (iv) verificar, a partir de um curso de formação continuada, se existe a possibilidade de diálogo entre um teórico-prático da educação, como Paulo Freire, e um teórico da epistemologia, Gaston Bachelard, e se esse diálogo poderia fazer parte das práticas educativas na escola.

Nesses termos, no primeiro artigo, a autora avaliou de que forma a Ciência, como saber social e pessoal na Educação Infantil e Anos Iniciais do Ensino Fundamental, discute a questão nas produções acadêmico-científicas do ENPEC e o que as pesquisas, na área de Educação em Ciências, mencionam acerca do ensino de Ciências nos Anos Iniciais. No segundo artigo, Maurente (2015) verificou, junto a 16 professores que atuam nos Anos Iniciais, no município de São Luiz Gonzaga/RS5 , a concepção de ciência e como essa concepção está inserida em suas práticas educativas, por meio da aplicação de questionário, composto de duas partes, em que um diz respeito ao perfil do profissional que atua nesse nível de ensino, e o segundo considera a concepção de ciência. Os dois primeiros

50 contato com essa realidade ocorreu em virtude do trabalho que vem sendo desenvolvido no Curso de Pedagogia e na Coordenação de Área do Programa Institucional de Bolsa de Iniciação à Docência (PIBID) na Universidade Estadual do Rio Grande do Sul - Unidade em São Luiz Gonzaga. 
artigos da pesquisadora, portanto, serviram como base para responder ao seguinte questionamento: quais as contribuições de um curso de formação continuada de professores que atuam nos Anos Iniciais acerca das concepções epistemológicas e sua relação com a prática pedagógica? Essa questão remeteu à elaboração de um terceiro artigo, no qual a autora teve a intenção de fomentar, por meio de um curso de formação continuada, outras possibilidades de se discutir e pensar a ciência na escola. No curso de formação continuada, objetivou discutir a História da Ciência, culminando com o diálogo entre Paulo Freire e Gaston Bachelard, na perspectiva de inclusão desses dois pensadores nas práticas educativas na escola.

$\mathrm{Na}$ tese T3, intitulada $A$ formação de professores dos anos iniciais do ensino fundamental em espaços não formais na Amazônia: investigando uma iniciativa no Centro de Ciência e Planetário do Pará, desenvolvida por Venturieri, (2019), a autora analisou as possibilidades e limites de uma proposta de formação continuada de professores dos anos iniciais do ensino fundamental, que busca ressignificação da relação entre 0 ensino de ciências em espaços não formais e a prática docente escolar. Para responder ao objetivo proposto, a pesquisadora trouxe três questões norteadoras: Qual a relação dos professores dos anos iniciais do Ensino Fundamental com o Centro de Ciências e Planetário do Pará-CCPP? De que forma este espaço de educação não formal pode contribuir para a formação continuada destes docentes? Que características seriam relevantes para que esta formação continuada possa auxiliar no desenvolvimento das necessidades profissionais destes professores? A pesquisa, desenvolvida entre os anos de 2016 e 2018, no Centro de Ciências e Planetário do Pará (CCPP), envolveu professores de Ciências que atuavam em turmas dos anos iniciais do ensino fundamental. A coleta de dados qualitativos foi realizada por meio da observação participante de questionários e entrevistas e, para a análise dos dados, a autora utilizou, como técnica, a análise de conteúdo.

Na sequência, as ações foram elaboradas com base no perfil dos professores e na análise crítica da realidade docente. 0 processo de formação ocorreu em cinco etapas, quatro presenciais e uma com atividades de orientação a distância. Os encontros presenciais tiveram duração de duas horas, totalizando 40 horas de formação; durante as atividades, os professores tiveram suas necessidades formativas atendidas, pois o CCPP, conforme a pesquisadora, contribuiu para um tipo de formação cuja reflexão sobre a prática pedagógica e sobre 0 incentivo a uma maior autonomia nas atividades didáticas, relacionadas ao ensino de ciências, foi exitosa. Dessa forma, Venturieri (2019) concluiu que 0 espaço investigado possui um grande potencial para o desenvolvimento de programas de formação continuada de professores.

Na tese T4, intitulada A construção coletiva de aulas para o ensino de ciências: uma proposta de formação continuada com professoras dos anos iniciais do ensino fundamental (PERSICHETO, 2016), a pesquisadora objetivou investigar de que maneira a elaboração e utilização de um acervo didático, a partir de uma experiência de formação continuada, realizada no contexto da escola, pode constituir-se como um suporte para o desenvolvimento profissional dos docentes. A pesquisa, desenvolvida por Persicheto (2016), baseou-se em estudos que revelaram que o professor dos anos iniciais é multidisciplinar e, geralmente, graduado em Pedagogia. Ressalta, ainda, que o professor finaliza a graduação com uma formação fragmentada para trabalhar com conteúdo de Ciências. Segundo a pesquisadora, conforme as intervenções realizadas, foi proposta às participantes uma elaboração de registros escritos, denominados registros reflexivos sobre as aulas desenvolvidas. Com isso, 0 grupo de professoras participantes da pesquisa integrou a elaboração compartilhada de um acervo didático com aulas de Ciências, identificado como um produto final de aprendizagem conjunta. 
0 questionamento, nesses termos, proposto por Persicheto (2016) é: como a construção coletiva de um acervo didático, elaborado a partir do desenvolvimento das aulas de Ciências, pode favorecer a formação e a atuação dos professores dos anos iniciais da Educação Fundamental e quais repercussões essa ferramenta de trabalho oferece em âmbito do Ensino de Ciências para esta etapa da escolarização? Na pesquisa qualitativa, de caráter colaborativo, e nos instrumentos de coleta de dados, foram utilizados questionários, observação participante, além de registros dos depoimentos escritos e orais que surgiram no decorrer do estudo. Os resultados, com referência à construção compartilhada de um Acervo Didático, juntamente com as demais ações integradas ao percurso de aprendizagem, representaram uma estratégia de formação produtiva e que pode repercutir positivamente no desenvolvimento profissional dos docentes. Portanto, conclui a autora que é possível a realização de um trabalho de qualidade para ensinar Ciências no contexto dos anos iniciais do Ensino Fundamental, considerando a pluralidade de estratégias e práticas desenvolvidas pelas professoras participantes e a repercussão positiva, evidenciada na aprendizagem dos estudantes.

Enfim, nas quatro teses analisadas, observou-se a predominância da pesquisa qualitativa, diferenciando-se apenas a T4, considerada quali-quantitativa. Isso ocorre, porque pesquisas dessa natureza primam pela interpretação dos dados e também pelo interesse dos pesquisadores quanto ao contexto da pesquisa, ou seja, ultrapassa a constituição dos dados brutos da pesquisa e almeja a sua compreensão, os motivos pelos quais os dados foram constituídos de determinada forma. Em cada pesquisa, os instrumentos auxiliares foram diversos, conforme Quadro 03, pois ocorreram encontros presenciais, rodas de diálogo, análise de documentos, abordagem por meio de roda de diálogo, entre outros métodos que favoreceram a abordagem dos professores e permitiram aos investigadores observar a sua prática e/ou acompanhar a sua participação na atividade proposta pelo pesquisador.

Com relação às tendências do ensino de Ciências para os anos iniciais, foram identificadas cinco (5) tendências principais: alfabetização científica; meio ambiente; corpo humano e saúde; evoluções científicas e tecnológicas e experimentação.

Ao analisar as entrevistas dos docentes participantes da pesquisa, Persicheto (2016) percebeu que os professores vinculam o ensino de Ciências a atitudes de preservação do meio ambiente, conhecimento do próprio corpo e manutenção da saúde. Também detectou que algumas professoras, ao serem questionadas sobre quais os objetivos do ensino de Ciências, na fase inicial de escolarização, estabeleceram relações com as discussões sobre a Alfabetização Científica dos alunos, na medida em que favorece a aproximação entre o conhecimento científico e o cotidiano, ou seja, uma formação voltada à cidadania.

Sabe-se que 0 conceito de Alfabetização Científica está em concordância com a definição proposta por autores, como Sasseron (2008), Lorenzetti (2000), Chassot (2000), Brandi e Gurgel (2002), Auler e Delizoicov (2001), Lorenzetti e Delizoicov (2001), defensores de um ensino de Ciências com objetivos voltados à formação cidadã dos estudantes, incentivando o uso de conhecimentos científicos em suas diversas faces, aplicando-os no decorrer de sua vida, ou seja, nas suas relações sociais, familiares, entre outras. Na investigação realizada por Maurente (2015), o ensino de Ciências é interpretado pelos professores pelo viés das evoluções científicas e tecnológicas, ou seja, é vinculada ao desenvolvimento científico do país e região e ao desenvolvimento científico mundial. As relações com o meio ambiente aparecem somente ao mencionar o tema transversal "Educação e Meio Ambiente". Na tese de Pereira (2014), o ensino de Ciências está vinculado à realização de atividades experimentais que, de acordo com os participantes da formação continuada, funcionam como elemento motivador para os estudantes. Em síntese, palestras sobre preservação do meio ambiente são relacionadas, 
por Venturieri (2019), ao modelo de formação clássico, em que o ensino de Ciências é interpretado sob o viés da divulgação científica e da popularização da Ciência.

\section{ANÁLISE DA FORMAÇÃO CONTINUADA A PARTIR DOS MODELOS CLÁSSICO, PRÁTICO-REFLEXIVO E EMANCIPATÓRIO}

Para compreender a formação continuada dos professores, segundo as teses analisadas, privilegiaram-se os três modelos de formação, propostos por Jacobucci (2006): 0 clássico, o prático-reflexivo e o emancipatório-político. Na determinação desses modelos, a autora utilizou como base 0 fato de que os modelos pedagógicos representam um conjunto de concepções diferenciadas de homem, de professor, de formação, de escola, de mundo, sendo estas influenciadas por questões políticas e ações geradas pelo ambiente onde cada docente se insere.

0 modelo clássico refere-se ao processo de formação continuada do professor, relacionando-0 à universidade e demais instituições formativas. Aborda a academia como detentora do conhecimento, cabendo aos professores a aplicação e transposição didática na sala de aula. Nesse modelo, o professor não transmite opinião sobre 0 que necessita para enriquecer a sua prática docente. Já o modelo prático-reflexivo aborda a formação do professor como sendo um processo que ocorre diariamente e representa os cursos como mediadores, capazes de incentivar a discussão de problemas reais que os docentes enfrentam na prática. Existe 0 interesse de que o professor faça reflexões sobre sua prática, enriqueça o fazer docente e aproxime a teoria da prática (JACOBUCCI, 2006).

0 modelo emancipatório-político, de acordo com a autora citada, considera o professor como um indivíduo em um ambiente coletivo, onde a cultura e as relações sociais determinam sua visão de mundo, a sua compreensão de realidade e o seu fazer docente. Nesse sentido, a sua formação busca a transformação da realidade escolar e social, ou seja, um modelo que valoriza tanto a teoria quanto a prática. Considerando o corpus da presente pesquisa, foi possível relacionar as quatro teses analisadas ao modelo de formação prático-reflexivo. Em T1, a autora propôs reflexões sobre a prática por meio da construção compartilhada de um acervo didático, o qual "buscou fornecer subsídio teórico-prático que influenciou nas práticas de sala de aula dos professores, com a intenção de contribuir para a formação de consciência ambiental nos alunos" (PERSICHETO, 2016, p. 209), permitindo aos docentes refletirem acerca de sua prática, realizarem troca de experiências e de conhecimentos, fato que enriquece o processo educativo.

Tardif (2008) reconhece a diversidade docente, reforçando o fato de que o professor, ao ser questionado sobre seus saberes, faz referência a conhecimentos e a um saber-fazer pessoal, o qual permite inferir que os professores demonstram confiança na sua própria experiência. Persicheto (2016) optou pela Formação Continuada de caráter colaborativo, realizada no contexto da escola, com 0 objetivo de compreender o contexto e se aproximar da realidade dos professores, de seus interesses e necessidades formativas, auxiliando na superação de suas dificuldades. Esse processo favoreceu situações de aprendizagem conjunta, estimulou um aprimoramento da prática pedagógica relacionada ao ensino de Ciências, sendo possível evidenciar que, quando compartilhada a experiência de trabalho de cada professor, representa uma referência importante na reconstrução dos saberes docentes direcionados ao ensino de Ciências.

Persicheto (2016) propôs o uso de diversas estratégias para organizar seu curso de formação continuada. Dentre elas, está a aplicação de um questionário direcionado aos participantes para favorecer a elaboração de um projeto de intervenção. Na sequência, buscou planejar ações que 
pudessem ocorrer, de forma conjunta, entre a pesquisadora e as docentes, com o objetivo de proporcionar momentos coletivos de discussão e aprendizagem, articulados com as ações pedagógicas realizadas em sala de aula (PERSICHETO, 2016). Outro aspecto a considerar foi a realização de encontros coletivos com as professoras participantes para discussão de temas e assuntos voltados ao ensino de Ciências, na etapa inicial da escolarização, com ênfase em estudos teóricos e propostas pedagógicas, capazes de auxiliar a troca de saberes e experiências, fato que acabou favorecendo 0 desenvolvimento profissional dos docentes participantes da pesquisa. Ocorreu, ainda, a elaboração de uma proposta de plano de aula, vinculada ao ensino de Ciências, à sua aplicação e à produção de registros reflexivos sobre 0 desenvolvimento das aulas, considerada como 0 início da construção do Acervo Didático, o qual contém os planos de aula, as atividades utilizadas, a indicação de sites, recursos, etc. (PERSICHETO, 2016).

Na pesquisa T2, foi possível inferir características do modelo de formação emancipatório-político, pois a autora buscou fornecer subsídio teórico-prático que influenciou as práticas de sala de aula dos professores, com a intenção de contribuir para a formação de consciência ambiental nos alunos. A autora buscou conhecer os professores com mais profundidade, por meio da apresentação da proposta de formação e da proposta de uma reflexão crítica de sua prática docente (VENTURIERI, 2019). É interessante mencionar que a pesquisa fez uso de estratégias, como a realização de encontros presenciais para apresentação da pesquisa e discussões sobre a prática docente. Também foi realizada uma visita de estudos, acompanhada das explicações sobre 0 que é necessário para a realização de tal tarefa, sob forma de uma atividade didática. Na sequência, como atividade não presencial, a autora propôs a elaboração de uma proposta de ação a ser desenvolvida no Centro de Ciências (VENTURIERI, 2019).

Em T3, a autora buscou outras possibilidades de se discutir a ciência na escola, utilizando, como estratégia, um curso de formação continuada, que teve como base a curiosidade de professores que atuam nos anos iniciais, oferecendo aos docentes meios para o desenvolvimento de estudos, discussões e reflexões, com o intuito de favorecer o ensino de Ciências na etapa inicial da Educação Básica (MAURENTE, 2015). A autora propôs um total de 13 encontros, nos quais realizou uma roda de conversa na intenção de constatar qual entendimento os professores construíram no decorrer dos encontros.

Em T4, foram oportunizadas aos professores ações formativas que visavam à ampliação dos seus conhecimentos em Ciências. A proposta de Pereira (2014) envolveu a articulação entre as diversas temáticas que conduzem 0 ensino de Ciências nos anos iniciais, mantendo suas escolhas vinculadas aos Parâmetros Curriculares Nacionais. A autora fez uso de diversos recursos para compreender a realidade do grupo de professores, como, por exemplo, o uso de relatos verbais, o qual "permitiu que cada participante problematizasse aspectos do seu cotidiano escolar, as dificuldades para a promoção de um ensino de Ciências nos anos iniciais de qualidade, bem como narrassem as suas atividades em sala de aula e na escola" (PEREIRA, 2014, p. 64). Sua proposta visou à implantação e avaliação do programa de formação continuada de professores em Ciências Naturais do Espaço Ciência InterAtiva.

Os cursos de formação continuada, oferecidos aos professores dos anos iniciais, foram elaborados sob a perspectiva de um modelo de formação crítico-reflexivo, fato que justifica a ausência de pesquisas vinculadas ao modelo de formação clássico e ao modelo de formação emancipatório-político, indicando uma busca crescente pela valorização dos conhecimentos prévios dos professores, ou seja, seu conhecimento oriundo de estudos anteriores e/ou de sua vivência e prática na sala de aula. Porém, quando cada pesquisador adentrou no universo escolar, deparou-se com professores em concordância com o modelo clássico e/ou com o modelo emancipatório-político. Por isso, é válida a compreensão 
de que a formação de professores corresponde ao processo de aprendizagem docente, e sua atuação, em uma perspectiva de estudo constante, é influenciada por políticas públicas (ARAUJO, 2013). Dessa forma, as propostas quanto à formação de professores envolvem processos de modificação e aperfeiçoamento para alcançar os diversos ideais a que se propõem esses recursos formativos, quando colocados em prática junto ao grupo de professores. Assim, para compreender o "que se tornam ao entrar na prática, é necessário conhecê-las, tais como foram concebidas pelos pedagogos revolucionários, pois são, com efeito, o fermento da evolução que as realiza" (DURKHEIN, 1995, p. 213-214).

\section{CONSIDERAÇÕES E ENCAMINHAMENTOS}

Compreender como o ensino de Ciências é abordado na formação continuada de professores, nos anos iniciais do Ensino Fundamental, constituiu-se no objetivo central deste estudo. A análise dos dados encontrados possibilitou a elaboração das considerações descritas a seguir.

Com relação às tendências para o ensino de Ciências nos anos iniciais, identificaram-se cinco (5) tendências: alfabetização científica, meio ambiente, evoluções científicas e tecnológicas, corpo humano e saúde e experimentação. A ênfase, nos aspectos identificados, enriquece o processo formativo docente e permite maior interação do professor-aluno, quando este aplica, em sala de aula, suas percepções durante e após a participação no curso de formação continuada. Especificamente, nos anos iniciais, essas tendências permitem estimular a curiosidade, o questionamento, as pesquisas e as percepções dos estudantes.

Quanto à abordagem e procedimentos de pesquisa, utilizados pelas autoras das teses selecionadas, verificou-se que a abordagem qualitativa é predominante nos estudos analisados, o que favorece a formação continuada de professores e com ela se relaciona. Essa abordagem, ainda que o processo formativo, nessa etapa da Educação Básica, seja discutido e contemplado na elaboração de teses e artigos científicos, enriquece a formação docente. 0 estudo também mostra que os cursos de formação continuada são meio para o levantamento de informações com a aplicação de questionários e realização de entrevistas.

Relativo ao modelo de formação continuada de professores, proposto por Jacobucci (2006), identificou-se, nas quatro teses analisadas, o modelo prático-reflexivo. No entanto, com os relatos das pesquisadoras, é possível inferir que, mesmo que as propostas de formação continuada tenham sido oferecidas sob a perspectiva do modelo prático-reflexivo, alguns docentes se constituíram como professores clássicos ou emancipatório-políticos.

Portanto, as propostas de formação continuada de professores, identificadas nas teses, favoreceram a reflexão sobre a prática docente, bem como uma provável alteração no comportamento em sala de aula, situação que pode contribuir com o ensino de Ciências nos anos iniciais, superando, inclusive, aspectos de insegurança docente, pois o processo formativo oferece elementos que proporcionam aos docentes material e segurança no desenvolvimento de suas aulas.

Ainda, cabe reafirmar que a educação, nos anos iniciais, demonstra complexidade por ser ministrada apenas por um docente, formado em Pedagogia, o qual é responsável pelo ensino de conteúdos de diferentes áreas do conhecimento. Com relação aos estudantes, é, nesta etapa da Educação Básica, que eles têm os primeiros contatos com os conhecimentos de Ciências, de maneira sistematizada, pois, até 0 ingresso na escola, a criança tem contato com diversas práticas e aplicações das Ciências, sem a devida compreensão ou explicação de fenômenos no seu dia a dia. Isso reforça a importância da formação continuada em Ciências dos professores dos Anos Iniciais 
do Ensino Fundamental, tendo em vista as constantes descobertas e a consequente evolução do conhecimento científico.

\section{REFERÊNCIAS}

AULER, J. P. ; DELIZOICOV, D. Alfabetização Científico-Tecnológica para quê? Ensaio: Pesquisa em Educação em Ciências, v. 3, n. 1, 2001.

ARAUJO, T. C. O. A prática do(a) coordenador(a) pedagógico(a) na Rede Municipal de Ensino do Rio de Janeiro: formação continuada de professores? 2013. 160 f. Tese (Doutorado em Educação) - Faculdade de Educação, Universidade do Estado do Rio de Janeiro, Rio de Janeiro, 2013.

BARDIN, L. Análise de conteúdo. São Paulo: Edições 70, 2011.

BIZZO, N. Ciências: fácil ou difícil. São Paulo: Biruta, 2009.

BRANDI, A. T. E.; GURGEL, C. M. A. A alfabetização científica e o processo de ler e escrever em séries iniciais: emergências de um estudo de investigação-ação. Ciência \& Educação, v. 8, n. 1, p. 113-125, 2002.

CHASSOT, Á. Alfabetização científica: questões e desafios para a educação. ljuí: Ed. Unijuí, 2000.

DURKHEIM, E. A evolução pedagógica. Porto Alegre: Artes Médicas, 1995.

GABINI, W. S.; DINIZ, R. E. da S. A formação continuada, o uso do computador e as aulas de ciências nos anos iniciais do ensino fundamental. Revista Ensaio. v. 14. n. 03. Belo Horizonte. p. 333-348. 2012. Disponível em: https://doi. org/10.1590/1983-21172012140320. Acesso em: 27. nov. 2020.

HAMBURGER, E. W. Apontamentos sobre o ensino de ciências nas séries escolares iniciais. Estudos Avançados, v. 21, n. 60, 2007. Disponível em: https://bit.ly/3nfYjPy. Acesso em: 04.mar.2021.

HERNÁNDEZ SAMPIERE, R.; FERNÁNDEZ COLLADO, C.; BAPTISTA LUCIO, M. del P. Metodologia da pesquisa. Porto Alegre: Penso, 2013

JACOBUCCI, D. F. C. A formação continuada de professores em Centros e Museus de Ciências no Brasil. 2006. 320p. Tese (Doutorado) - Universidade Estadual de Campinas, Faculdade de Educação, Campinas, SP. Disponível em: https:// bit.ly/3pj7v8r. Acesso em: 23 abr. 2021.

LIMA, M. da C. B.; CARVALHO, A. M. P. de. Exercícios de raciocínio" em três linguagens: ensino de física nas séries iniciais. Ensaio - Pesquisa em Educação em Ciências. v. 1, n. 4, 2002.

LIMA, S. C. de; NARDI, R. Formações imaginárias de professores dos anos iniciais do ensino fundamental sobre a forma de Terra e 0 conceito de gravidade. Revista Ensaio. v. 22. Belo Horizonte, p. 01-24. 2020. Disponível em: http:// dx.doi.org/10.1590/21172020210129. Acesso em: 27. nov. 2020.

LORENZETTI, L. Alfabetização científica no contexto das séries iniciais. 2000. Dissertação (Mestrado em Educação) Universidade Federal de Santa Catarina, Florianópolis, 2000. 
LORENZETTI, L.; DELIZOICOV, D. Alfabetização científica no contexto das séries iniciais. Ensaio: Pesquisa em Educação em Ciências, v. 3, n. 1, p. 37-50, 2001.

MAURENTE, V. M. M. As contribuições de um curso de formação continuada de professores que atuam nos anos iniciais acerca das concepções epistemológicas e sua relação com a prática pedagógica. 2015. 135 f. Tese (Doutorado em Educação em Ciências: Química da Vida e Saúde) - Instituto de Ciências Básicas da Saúde, Universidade Federal do Rio Grande do Sul, Porto Alegre, RS, 2015.

MARTINS, J. P. de A. Educação ambiental crítica e formação continuada de professoras fundada na investigação-ação e na parceria colaborativa. 2016. 253 f. Tese (Doutorado em Educação) - Universidade Metodista de Piracicaba, Faculdade de Ciências Humanas, Piracicaba, SP, 2016.

PERSICHETO-0JA, A. J. A construção coletiva de aulas para 0 ensino de ciências: uma proposta de formação continuada com professoras dos anos iniciais do ensino fundamental. 2016. 249 f. Tese (Doutorado em Educação para a Ciência) - Faculdade de Ciências, Universidade Estadual Paulista, Bauru, 2016.

PEREIRA, G. R. 0 ensino de ciências nos anos iniciais 0 ensino fundamental e a formação continuada de professores: implantação e avaliação do programa formativo de um Centro de Ciência. 2014. $231 \mathrm{f}$. Tese (Doutorado em Ciências Biológicas) - Universidade Federal do Rio de Janeiro, Rio de Janeiro, 2014.

PEREIRA, G. R.; PAULA, L. M. de; PAULA, L. M. de; COUTINHO-SILVA, R. Formação de professores dos anos iniciais da educação básica: impacto do programa formativo de um museu de ciência a partir do viés crítico-reflexivo. Revista Ensaio. v. 19. Belo Horizonte. p. 1-22. 2017. Disponível em: https://doi.org/10.1590/1983-21172017190115. Acesso em: 27. nov. 2020.

ROSA, C. W.; PEREZ, C. A. S.; DRUM, C. Ensino de física nas séries iniciais: concepções da prática docente. Investigações em Ensino de Ciências, v. 12, n. 3, p. 357-368, 2007.

SASSERON, L. H. Alfabetização científica no ensino fundamental: estrutura e indicadores deste processo em sala de aula. 2008. Tese (Doutorado em Educação) - Universidade de São Paulo, São Paulo, 2008.

TARDIF, M. Saberes docentes e formação profissional. Petrópolis, RJ: Vozes, 2008.

VENTURIERI, B. A formação de professores dos anos iniciais do ensino fundamental em espaços não formais na Amazônia: investigando uma iniciativa no centro de ciências e planetário do Pará. 2019. 165 f. Tese (Doutorado em Educação para a Ciência) - Faculdade de Ciências, Universidade Estadual Paulista "Julio de Mesquita Filho", Bauru, SP, 2019.

RECEBIDO EM: 26 maio 2021

CONCLUÍDO EM: 12 out. 2021 